\title{
Differential Effects of Cold Stress on the Antioxidant Response of Mycorrhizal and Non-Mycorrhizal Jatropha curcas (L.) Plants
}

\author{
H. Pedranzani ${ }^{1}$, N. Tavecchio ${ }^{3}$, M. Gutiérrez ${ }^{3}$, M. Garbero ${ }^{3}$, R. Porcel $^{2}$, \& J. M. Ruiz-Lozano ${ }^{2}$ \\ ${ }^{1}$ Laboratorio de Fisiología Vegetal, Facultad de Química Bioquímica y Farmacia, Universidad Nacional de San \\ Luis, San Luis, Argentina \\ ${ }^{2}$ Departamento de Microbiología del Suelo y Sistemas Simbióticos, Estación Experimental del Zaidín (CSIC), \\ Granada, Spain \\ ${ }^{3}$ Laboratorio de Fisiología Vegetal, Departamento de Ciencias Agropecuarias, Facultad de Ingenieria y Ciencias \\ Agropecuarias, Universidad Nacional de San Luis, San Luis, Argentina \\ Correspondence: H. Pedranzani, Laboratorio de Fisiología Vegetal, Facultad de Química Bioquímica y Farmacia, \\ Universidad Nacional de San Luis, Ejército de los Andes 950 (5700), San Luis, Argentina. E-mail: \\ hepedra@unsl.edu.ar
}

Received: March 17, 2015 Accepted: May 13, 2015 Online Published: July 15, 2015

doi:10.5539/jas.v7n8p35 URL: http://dx.doi.org/10.5539/jas.v7n8p35

\begin{abstract}
Our main objective was to analyze the protection provided by Mycorrhiza (Rhizophagus intraradices) to Jatropha curcas plants under cold stress, through the analysis of physiological and oxidative stress parameters. Mycorrhizal (AM) and non-mycorrhizal (nonAM) plants were exposed to cold stress $4 \pm 1^{\circ} \mathrm{C}$ temperature for 72 h. The control plant grow at $25 \pm 1{ }^{\circ} \mathrm{C}$. Under cold stress, the stomata conductance decreased both AM and nonAM plants and photosynthetic efficiency only in non AM plants. The CAT activity increased in AM plants independently of stress conditions. GR activity shows a typical rise to cold stress in nonAM plants and decreased in AM ones. With cold stress, the APX activity was reduced in all treatments and SOD activity was not affected in all treatment The MDA content increased in nonAM plants while in AM plants it was unaffected by low temperature. This study reported on the regulation of antioxidant compounds, their relationship to the AM symbiosis and cold stress in Jatropha curcas L.
\end{abstract}

Keywords: antioxidant response, arbuscular mycorrhizae, cold stress, Jatropha curcas

\section{Introduction}

Jatropha curcas L. is native from Mexico and Central America but grows in most tropical countries. It is cultivated in Central America, South America, Southeast Asia, India and Africa (Heller, 1996). It is a perennial shrub or small tree and reaches up to $5 \mathrm{~m}$ height. The leaves are deciduous, and have 5-7 lobes acuminate (Prakash et al., 2007). The renewed interest in its cultivation is mainly due to the fact that it is a perennial species adapted to marginal conditions for agriculture and to its ability for oil accumulation, which makes the plant suitable for biodiesel production. The seeds contain 30-35\% oils which can be used as raw material for biodiesel production (Azam et al., 2005). Plant performance is reduced by cold stress, one of the most serious environmental abiotic stresses that plants have to cope with throughout their life cycle. Cold stress limits the agronomic yield by reducing the plant growth with negative and unforeseeable effects on biomass accumulation (Bracale \& Coraggio, 2003). In $J$. curcas seedlings, low temperature reduces leaf chlorophyll content, unsaturated fatty acid content and produces increase in permeability of cell membranes (Tong et al., 2005), indicating that this species is sensitive to cold stress. Low temperature is an environmental stress that affects crop production quality and produced anatomical, biochemical, physiological and hormonal plant changes. Several studies showed that cold exposure affects sorghum plants growth and produces marked loss in dry weight and leaf area (Ercoli et al., 2004). Similarly, in wheat cultivars, cold reduced shoot relative growth rate (Equiza et al., 2001). Leaves of plants grown at low temperature are characterized by a very low photosynthetic performance and changes in pigment composition (Haldimann et al., 1996) and pigment content (Oliveira et al., 2009). For example, chlorophyll $a+b$ and total carotenoids contents were higher in Zea mays chilling-tolerant than in other genotypes (Haldimann, 1999). Many studies have demonstrated the involvement of antioxidant defence system in response to suboptimal temperatures. E.g., the exposure of Digitaria eriantha to cold caused 
increased malondialdehyde (MDA) content, differential response in antioxidant defence, chlorophyll synthesis and serious anatomical damage in leaves (Garbero et al., 2011, 2012). Reactive oxygen species (ROS) attack proteins, lipids and nucleic acids, and the degree of damage depends on the balance between formation of ROS and their removal by the antioxidative scavenging systems and this appears to represent an important stress-tolerance trait (Scheibe \& Beck, 2011). Expression of antioxidant defense genes would, in turn, be triggered to defend the cell against oxidative damage (Menezes-Benavente et al., 2004). In plant cells, ROS detoxification is controlled by ROS scavenging enzymes such as superoxide dismutase (SOD), catalase (CAT), peroxidase (POD) and the Asada-Halliwell scavenging cycle. This cycle is found in different cellular organelles and the cytosol (Hamilton \& Heckathorn, 2001) and involves the oxidation and reduction of ascorbate and glutathione mainly by the activities of ascorbate peroxidase (APX) and glutathione reductase (GR) (Asada, 1999). Lipid peroxidation is generally estimated in term of malondialdehyde (MDA) content (Halliwell \& Gutteridge, 2007).

In recent years, the use of arbuscular mycorrhizal (AM) fungi has received increased attention because AM plants are frequently more tolerant to abiotic stresses than nonAM plants. Thus, in Phaseolus vulgaris seedlings, the AM symbiosis regulated root hydraulic properties and enhanced root hydraulic conductance under cold, drought and salinity stresses (Aroca et al., 2007). In addition, in maize plants inoculated with Glomus etunicatum, MDA content remained lower in AM plants than that in nonAM plants under a wide range of temperatures studied $\left(5-40{ }^{\circ} \mathrm{C}\right)$, which shows that the presence of the AM fungus could alleviate the peroxidation of membrane lipids (Zhu et al., 2010). These authors, found low proline content and high superoxide dismutase (SOD), catalase (CAT), and peroxidise (POD) activity in leaves of AM maize plants exposed to low temperature. There are also reports showing regulation of non-enzymatic antioxidant compounds by the AM symbiosis under drought stress (Ruiz-Sánchez et al., 2010; Baslam et al., 2012).

Given the sensitivity to low temperatures of $J$. curcas, we investigated the AM colonization in $J$. curcas and we evaluated the effects of mycorrhization in plants of $J$. curcas subjected to cold stress.

\section{Materials and Methods}

\subsection{Soil and Biological Materials}

Loamy soil was collected from Granada province (Spain), sieved $(5 \mathrm{~mm})$, diluted with quartz-sand $(<2 \mathrm{~mm})$ (1:1), soil:sand, $\mathrm{v} / \mathrm{v})$ to avoid excessive compaction and sterilized by steaming $\left(100{ }^{\circ} \mathrm{C}\right.$ for $1 \mathrm{~h}$ on 3 consecutive days). The original soil had a $\mathrm{pH}$ of 8.2 [measured in water $1.5(\mathrm{w} / \mathrm{v})$ ]; $1.5 \%$ organic matter, nutrient concentrations $\left(\mathrm{g} \mathrm{kg}^{-1}\right): \mathrm{N}, 1.9 ; \mathrm{P}, 1.0 ; \mathrm{K}, 6.9$, The electrical conductivity of the soil was $200 \mu \mathrm{S} \mathrm{cm}^{-1}(1: 5, \mathrm{w} / \mathrm{v})$ (Aroca et al., 2013). Seeds of Jatropha curcas L. were washed for $3 \mathrm{~min}$ in pure ethanol and rinsed three times with distilled water. Seeds were then sown in $1000 \mathrm{ml}$ pots containing a sterilized mixture of soil/sand $(1: 1, \mathrm{v} / \mathrm{v})$. Mycorrhizal inoculum of (Rhizophagus intraradicves) (Schenck and Smith) Walker \& Schüßler, isolate BEG 123 was prepared as described by Porcel et al. (2006). Ten grams of the inoculum were added to $J$. curcas seedlings. Non inoculated plants were also cultivated as controls (nonAM) and a filtrate of the AM inoculums was added to nonAM plants. After cultivation under normal greenhouse conditions at $25 \pm 2{ }^{\circ} \mathrm{C}$ during 40 days, half of plants was transferred to a growth chamber at $5{ }^{\circ} \mathrm{C}$ (day:night) for $72 \mathrm{~h}$, under a cycle of $16: 8 \mathrm{~h}$ (day : night) with a photosynthetic photon flux density (PPFD) of $300 \mu \mathrm{mol} \mathrm{m} \mathrm{m}^{-2} \mathrm{~s}^{-1}$ and keeping the soil to full water capacity. After that, the different measurements were taken at control conditions (at $\left.25 \pm 2{ }^{\circ} \mathrm{C}\right)$ and cold stress conditions $\left(5^{\circ} \mathrm{C}\right)$. The experiment consisted of a randomized complete block design with four replications per treatment.

\subsection{Mycorrhizal Development}

The percentage of mycorrhizal root infection was estimated by visual observation of fungal colonization alter clearing washed roots in $10 \% \mathrm{KOH}$ and staining whit $0.05 \%$ trypan blue in lactic acid $(\mathrm{v} / \mathrm{v})$, according to Philips and Hayman (1970). The extent of mycorrhizal colonization was calculated according to the gridline intersect method (Giovannetti \& Mosse, 1980).

\subsection{Fresh and Dry Weights}

Plants were separated in leaves and roots and fresh weights (FW) were recorded to study the performance of inoculated plants. Plant samples were dried in an oven at $60^{\circ} \mathrm{C}$ until constant dry weight (DW) was obtained.

\subsection{Stomatal Conductance and Photosynthetic Efficiency}

Stomatal conductance was measured two hours after the light turned on by using a porometer system (Porometer AP4, Delta-T Devices Ltd., Cambridge, UK) following the user manual instructions. Stomatal conductance measurements were taken in the last fully developed leaf. The efficiency of photosystem II was measured with FluorPen FP100 (Photon Systems Instruments, Brno, Czech Republic), which allows a non-invasive assessment 
of plant photosynthetic performance by measuring chlorophyll a fluorescence. FluorPen quantifies the quantum yield of photosystem II as the ratio between the actual fluorescence yield in the light-adapted state $\left(F^{\prime}{ }_{V}\right)$ and the maximum fluorescence yield in the light-adapted state $\left(F^{\prime}{ }_{M}\right)$, according to Oxborough and Baker (1997). Measurements were taken in the last fully developed leaf

\subsection{Oxidative Damage to Lipids}

Lipid peroxides were extracted by grinding $500 \mathrm{mg}$ of leaves with and ice-cold mortar and $6 \mathrm{~mL}$ of $100 \mathrm{mM}$ potassium phosphate buffer ( $\mathrm{pH} 7$ ). Homogenates were filtered through one Miracloth layer and centrifuged at $15,000 \mathrm{~g}$ for $20 \mathrm{~min}$. The chromogen was formed by mixing $200 \mu \mathrm{L}$ of supernatants with $1 \mathrm{~mL}$ of a reaction mixture containing $15 \%(\mathrm{w} / \mathrm{v})$ trichloroacetic acid (TCA), $0.375 \%(\mathrm{w} / \mathrm{v}) 2$-thiobarbituric acid (TBA), $0.1 \%(\mathrm{w} / \mathrm{v})$ butyl hydroxytoluene, $0.25 \mathrm{~N} \mathrm{HCl}$ and by incubating the mixture at $100{ }^{\circ} \mathrm{C}$ for $30 \mathrm{~min}$ (Minotti and Aust, 1987). After cooling at room temperature, tubes were centrifuged at $800 \mathrm{~g}$ for $5 \mathrm{~min}$ and the supernatant was used for spectrophotometric readings at $532 \mathrm{~nm}$. Lipid peroxidation was estimated as the content of 2-thiobarbituric acid-reactive substances (TBARS) and expressed as equivalents of malondialdehyde (MDA) according to Halliwell and Gutteridge (1989). The calibration curve was made using MDA in the range of 0.1-10 nmol. A blank for all samples was prepared by replacing the sample with extraction medium, and controls for each sample were prepared by replacing TBA with $0.25 \mathrm{~N} \mathrm{HCl}$. In all cases, $0.1 \%(\mathrm{w} / \mathrm{v})$ butyl hydroxytoluene was included in the reaction mixtures to prevent artifactual formation of TBARS during the acid-heating step of the assay.

\subsection{Enzyme Assays}

Enzymes were extracted at $0-4{ }^{\circ} \mathrm{C}$ from $1 \mathrm{~g}$ (fresh weight) shoot tissues using a mortar and pestle with $50 \mathrm{mg}$ polyvinylpolypyrrolidone (PVPP) and $10 \mathrm{ml}$ of the following optimized medium: $50 \mathrm{mM} \mathrm{K}$-phosphate buffer $\mathrm{pH}$ 7.8 containing $0.1 \mathrm{mM}$ EDTA for superoxide dismutase (SOD) and catalase (CAT). The same medium supplied with $4 \mathrm{mM}$ ascorbic acid was used for ascorbate peroxidase (APX) and supplied with $10 \mathrm{mM}$ mercaptoethanol was used for glutathione reductase (GR) (Porcel et al., 2003). Extracts were filtered through four layers of nylon cloth and centrifuged at $20,000 \mathrm{~g}, 20 \mathrm{~min}, 0-4{ }^{\circ} \mathrm{C}$. The supernatants were kept at $-70{ }^{\circ} \mathrm{C}$ for subsequent enzymatic assays.

Total SOD activity (EC 1.15.1.1) was measured according to Beyer and Fridovich (1987) based on the ability of SOD to inhibit the reduction of nitroblue tetrafolium (NBT) by superoxide radicals generated photochemically. One unit of SOD was defined as the amount of enzyme required to inhibit the reduction rate of NBT by $50 \%$ at $25{ }^{\circ} \mathrm{C}$. CAT activity (EC 1.16.1.6) was measured by the disappearance of $\mathrm{H}_{2} \mathrm{O}_{2}$ (Aebi, 1984). The reaction mixture $(3 \mathrm{ml})$ contained $10.6 \mathrm{mM} \mathrm{H} \mathrm{H}_{2} \mathrm{O}_{2}$. The reaction was initiated by adding $25 \mu \mathrm{l}$ of the extract and monitoring the change in absorbance at $240 \mathrm{~nm}$ and $25^{\circ} \mathrm{C}$ for $3 \mathrm{~min}$. APX activity (EC 1.11.1.11) was measured

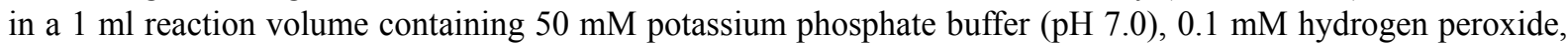
and $0.5 \mathrm{mM}$ ascorbate. Adding the $\mathrm{H}_{2} \mathrm{O}_{2}$ started the reaction and the decrease in absorbance at $290 \mathrm{~nm}$ was recorded for $1 \mathrm{~min}$ to determine the oxidation rate of ascorbate (Amako et al., 1994). Finally, GR activity (EC 1.6.4.2) was determined by the procedure of Carlberg and Mannervik (1985). The reaction mixture (1 ml) contained $0.1 \mathrm{M}$ HEPES $\mathrm{pH} 7.8,1 \mathrm{mM}$ EDTA, $3 \mathrm{mM} \mathrm{MgCl} 2,0.5 \mathrm{mM}$ oxidized glutathione, $0.2 \mathrm{mM}$ NADPH and $150 \mu \mathrm{l}$ of the enzyme extract. The rate of NADPH oxidation was monitored by the decrease in absorbance at $340 \mathrm{~nm}$ for $2 \mathrm{~min}$. Two blanks, one without the enzyme extract and the other without oxidized glutathione were used as controls.

\subsection{Statistical Analysis}

Analysis of variance (ANOVA) was used and data were subjected to Multiple Range Test. The software used was Statgraphics Plus, Version 3 (Manugistics, Rockville, MD, USA).

\section{Results}

No mycorrhizal colonization was observed in plants not provided with AM inoculums. Mycorrhizal plant showed about $60 \%$ of mycorrhizal root length under both control and cold-stressed conditions.

The cold stress treatment lasted only $72 \mathrm{~h}$ and did not affect plant biomass production. Thus, only effects of AM inoculation were observed. Roots FW and DW increased in AM plants respect to nonAM plants (Figures $1 \mathrm{~A}$ and 1B) in a percentage higher to $100 \%$. The aerial FW and DW also increased significantly in AM plants in a percentage of $30 \%$ respects no AM plants (Figures 1C and 1D). 


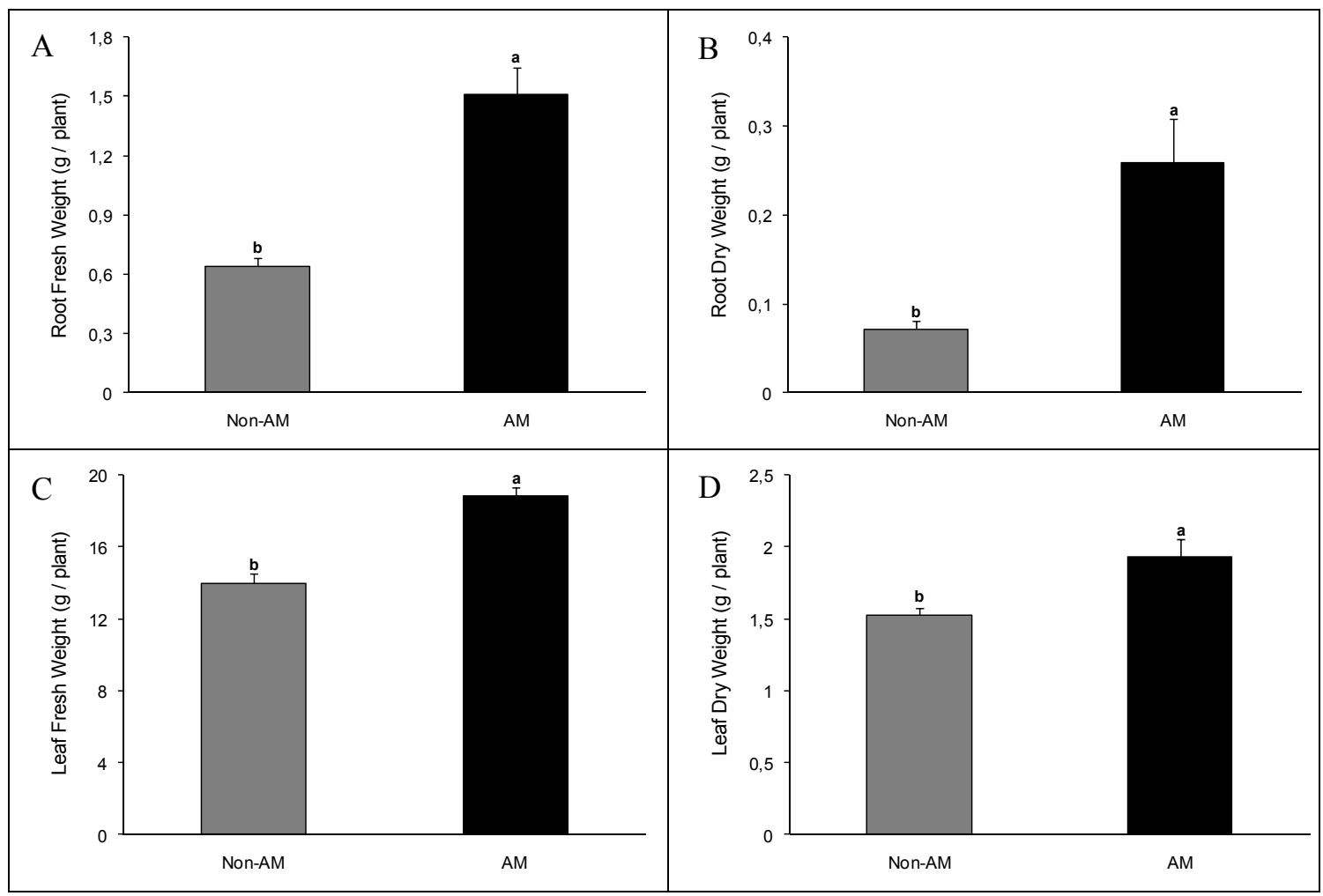

Figure 1. Root fresh weight (A), Root dry weight (B), Leaves fresh weight (C), and Leaves dry weight (D) of Jatropha curcas cultivated under control conditions or subjected to cold stress for $72 \mathrm{~h}$. Values shown are mean \pm SE from triplicate experiments, and different letters indicates significant difference at $\mathrm{p} \leq 0.05$

No significant differences were found between AM and nonAM plants for the stomatal conductance at optimal and suboptimal temperatures. However under cold stress conditions, both AM and nonAM plant decreased the stomatal conductance whit respect to control plants (Figure 2A). Photosynthetic efficiency showed a decrease in nonAM plants subjected to cold stress for $72 \mathrm{~h}$. Efficiency was not significantly changed in AM plants under cold treatment (Figure 2B).

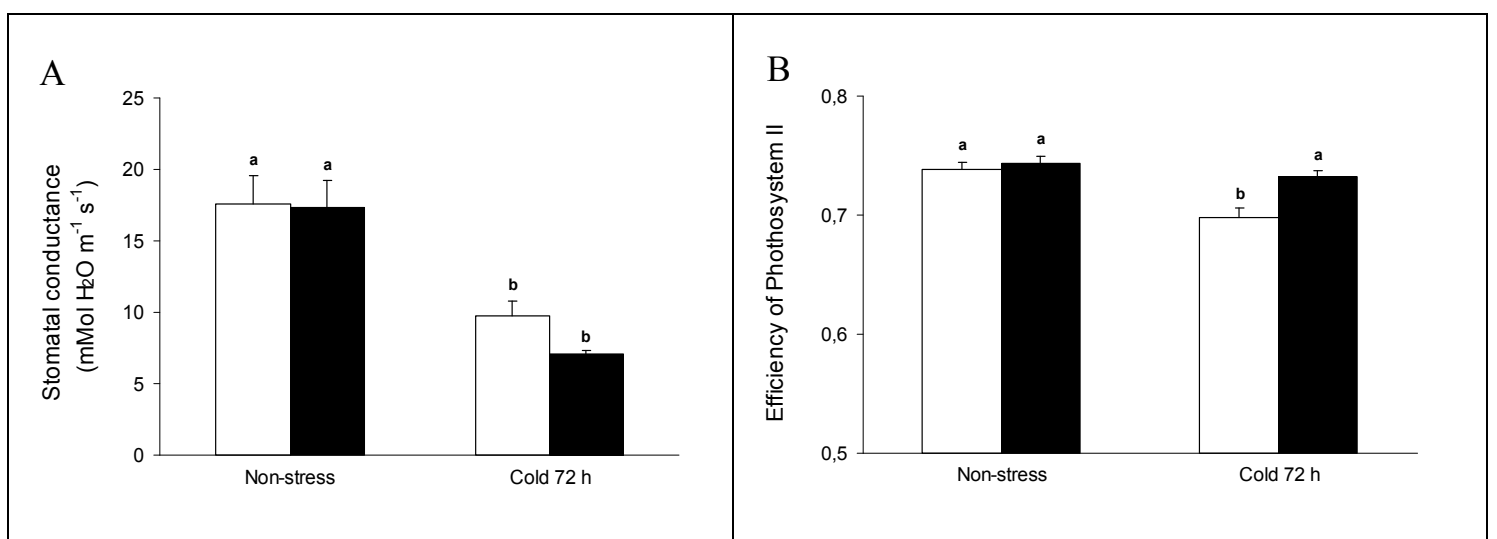

Figure 2. Stomatal conductance $\mathrm{mMol} \mathrm{H}_{2} \mathrm{O} \mathrm{m}^{-2} \mathrm{~s}^{-1}$ (A) and Efficiency of photosystem II (B) in leaves of Jatropha curcas cultivated under control conditions or subjected to cold stress for $72 \mathrm{~h}$. White bars Non-AM plants, black bars AM plants. Values shown are mean $\pm \mathrm{SE}$ from triplicate experiments, and different letters indicates significant difference at $\mathrm{p} \leq 0.05$

Under cold stress, MDA content increased by $81 \%$ in nonAM plants as compared to control plants. In contrast, MDA content was not affected by low temperature in mycorrhizal plants (Figure 3). 


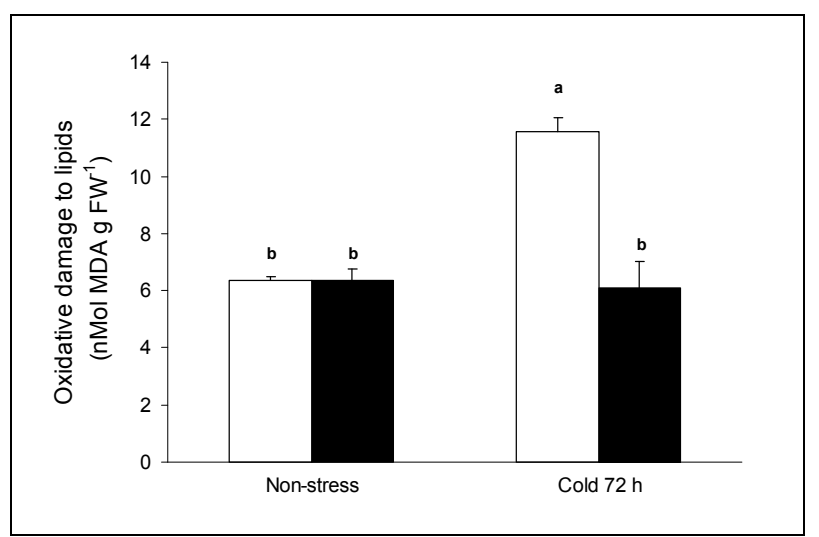

Figure 3. Oxidative damage to lipids (nmol MDA $\mathrm{g} \mathrm{FW}^{-1}$ ) in leaves of Jatropha curcas cultivated under control conditions or subjected to cold stress for $72 \mathrm{~h}$. White bars Non-AM plants, black bars AM plants

The CAT activity resulted consistently enhanced in AM plants both under control and under cold stress conditions. However, no effect of cold stress on this enzymatic activity was observed (Figure 4A). The GR activity was significantly enhanced by mycorrhization under control conditions. In contrast, under cold stress conditions, GR increased only in nonAM plants and decreased in AM ones (Figure 4B).

The APX activity was lower in AM plants under control conditions. The cold stress treatment decreased such activity in AM and nonAM plants, with no further effects due to mycorrhization (Figure 4C).

The SOD activity was lower in AM plants than in nonAM ones under control conditions. The cold stress treatment did not affect this activity in any treatment (Figure 4D).

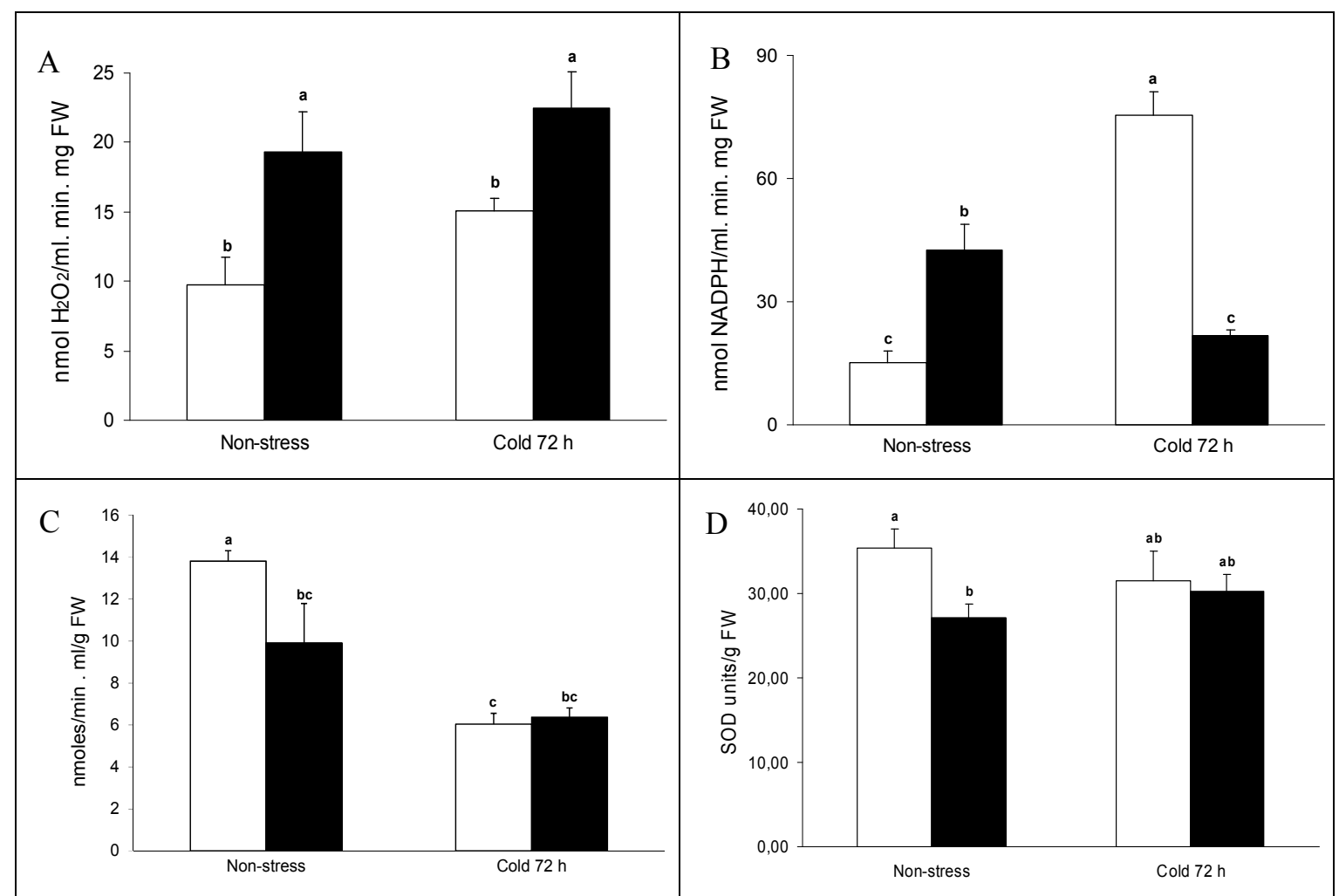

Figure 4. Total activity of CAT (A), GR (B), APX (C), and SOD (D) per g of WF in leaves of Jatropha curcas cultivated under control conditions or subjected to cold stress for $72 \mathrm{~h}$. White bars Non-AM plants, black bars AM plants 


\section{Discussion}

Symbiotic interactions between $J$. curcas plants and $R$. intraradices under cold stress were studied in the present work. Our results showed $60 \%$ of AM roots colonization at 70 days after sowing. This high rate of fungal root colonization will probably enhance AM effects on plants development (Smith \& Read, 2010).

Previously, Kumar et al. (2010) demonstrated that $J$. curcas seedlings inoculated with AM fungi (Glomus intraradices among other species) had greater survival, shoot length, shoot diameter, and shoot, root, and plant dry weights than nonAM seedlings, indicating that AM plants grow better than nonAM plants under saline conditions and that $J$. curcas is a mycotrophic species. Our results showed increased of FW and DW in AM plant as compared to nonAM plants. This effect of AM on DW was more pronounced in roots biomass than in aerial biomass, probably because AM colonization caused a proportionally greater allocation of carbohydrates to the root than leaf tissues. Alteration in stomatal conductance plays a key role in regulating plant metabolism during abiotic stress. Under cold stress conditions we found reduced stomatal conductance in both AM and nonAM plants of $J$. curcas. Chaves et al. (2009) suggested that under mild salinity stress, a small decline in stomatal conductance may have protective effects against stress, by allowing plant water saving and improving plant water-use efficiency. Gao et al. (2013) showed in J.curcas plants decreases in chlorophyll content in non-mycorrhizal plants under low temperature. Moreover, the ability to maintain photosynthetic efficiency under stressful situations is a desirable characteristic in tolerant plants. In our study, AM plants did not reduce their photosynthetic efficiency at suboptimal temperatures. The higher values of photosynthetic efficiency in AM plants under cold indicate that the photosynthetic apparatus of these plants was less damaged by the stress imposed than in nonAM plants. Moreover, at long term, a high efficiency of photosystem II may results in enhanced plant growth. Indeed, it has been shown that maintenance of photosynthetic efficiency also keeps plant productivity (Loggini et al., 1999).

The oxidation of membrane lipids is a reliable indication of uncontrolled free radical production, and hence, of oxidative stress (Noctor \& Foyer, 1998). Zheng et al. (2009) and Gao et al. (2013) found decreases in photosynthetic parameters and increases in MDA content in populations of $J$. curcas subjected to low temperature. In addition, different studies suggested that AM symbiosis could alleviate the peroxidation of lipids. In maize and tomato plants, under low temperature stress, increased MDA content was found, but AM plants had lower MDA content as compared to nonAM plants (Zhu et al. 2010; Latef \& Chaoxing, 2011). Consistent with this, in this study increased in MDA content was only found in nonAM plants subjected to cold stress. Thus, the antioxidant defences were more effective in AM plants than in the nonAM plants.

Antioxidant enzymes such as SOD, APX, CAT, and GR prevent damage from ROS. Latef and Chaoxing (2011) reported increased in antioxidant enzymes activities under low temperature in AM tomato plants, and Chen et al. (2014) suggested that AM symbiosis could decrease the accumulation of ROS and reduce the oxidative damage in maize plants under cold stress by a variety of antioxidant compounds in different ways. The result obtained in the present study in relation of these antioxidant activities showed that under cold stress only CAT activity was higher in mycorrhizal plants than in the non mycorrhizal ones. This may explain, at least partially, why MDA levels were not enhanced by cold stress in AM plants. However, the lower MDA contents in AM plants can be due not only to the activity of antioxidant enzymes, but also to the accumulation of non-enzymatic antioxidant compounds such as ascorbate or glutathione. Ascorbate is an important antioxidant compound involved in the removal of $\mathrm{H}_{2} \mathrm{O}_{2}$ by ascorbate peroxidases, which use it as electron donor (Foyer and Noctor, 2011). Glutathione has the functions of scavenging peroxides and regenerating ascorbate pool. It also may keep the cell pools of reducing power (NADPH) under the necessary conditions for plant cells (Foyer and Noctor, 2011). Thus, AM $J$. curcas plants could be accumulating these antioxidant compounds under cold stress to prevent lipid peroxidation. These compounds were not measured in this study, but a higher accumulation in AM plants subjected to drought stress has been reported in several plant species (Wu \& Zou, 2009; Ruiz-Sánchez et al., 2011; Baslam et al., 2012). Moreover, a recent study has shown that the benefits of AM symbiosis not only rely in a lower oxidative stress in the host plant, but also restrict locally such oxidative stress, avoiding a systemic damage and allowing the plants to continue with their physiological processes (Bárzana et al., 2015). These results indicate that AM inoculation lead a well-established defence mechanism against the cold and that mitigation of oxidative stress might be a crucial part of the beneficial action of AM symbiosis.

The stability in photosynthetic efficiency, antioxidant defence system and MDA content suggests that $J$. curcas plants inoculated with $R$. intraradices are better protected against cold stress injury. This should be taken into account to improve $J$. curcas development and productivity in order to enhance biofuels production in temperate areas. 


\section{Acknowledgements}

This work was funded by the Erasmus Mundus External Coorporation project, meaning through a grant to Dr. Hilda E. Pedranzani for a postdoctoral stay at the CSIC, Granada, Spain, with the direction of Dr. Juan Manuel Ruiz Lozano.

\section{Abbreviations}

AM, arbuscular mycorrhizal; APX, ascorbate peroxidase; CAT, catalase; GR, glutathione reductase; MDA, malondialdehyde; NonAM, noninoculated plants; SOD, superoxide dismutase.

\section{References}

Aebi, H. (1984). Catalase in vitro. Methods in Enzymology, 105, 121-126.

Amako, K., Che, G. X., \& Asada., K. (1994). Separate assays specific for ascorbate peroxidase and guaiacol peroxidase and for the chloroplastic and cytosolic isoenzymes of ascorbate peroxidase in plants. Plant and Cell Physiology, 35, 497-504.

Aroca, R., Porcel, R., \& Ruiz-Lozano, J. M. (2007). How does arbuscular mycorrhizal symbiosis regulate root hydraulic properties and plasma membrane aquaporin in Phaseolus vulgaris under drought, cold or salinity stresses? New Phytol, 173, 808-816. http://dx.doi.org/10.1111/j.1469-8137.2006.01961.x

Aroca, R., Ruiz-Lozano, J. M., Zamarreño, A. M., Paz, J. A., Garcia-Mina, J. M., Pozo, M. J., \& Lopez-Raez, J. A. (2013). Arbuscular mycorrhizal symbiosis influences strigolactone production under salinity and alleviates salt stress in lettuce plants. Journal of Plant Physiology, 170, 47-55. http://dx.doi.org/10.1016/j.jplph.2012.08.020

Azam, M. M., Waris, A., \& Nahar, N. M. (2005). Prospects and potential of fatty acid methylesters of some non-traditional seed oils for use as biodiesel in India. Biomass and Bioenergy, 29, $293-302$. http://dx.doi.org/10.1016/j.biombioe.2005.05.001

Bárzana, G., Aroca, R., \& Ruiz-Lozano, J. M. (2015). Localized and non-localized effects of arbuscular mycorrhizal symbiosis on accumulation of osmolytes and aquaporins and on antioxidant systems in maize plants subjected to total or partial root drying. Plant Cell and Environment. http://dx.doi.org/10.1111/pce.12507

Baslam, M., \& Goicoechea, N. (2012). Water deficit improved the capacity of arbuscular mycorrhizal fungi (AMF) for inducing the accumulation of antioxidant compounds in lettuce leaves. Mycorrhiza, 22, 347-359. http://dx.doi.org/10.1007/s00572-011-0408-9

Beyer, W. F., \& Fridovich, I. (1987). Assaying for superoxide dismutase activity: some large consequences of minor changes in conditions. Analytical Biochemistry, 161, 559-566. http://dx.doi.org/10.1016/0003-2697(87)90489-1

Bracale, M., \& Coraggio, L. (2003). Chilling and freezing stresses in plantas: Cellullar response and molecular strategies for adaptation. In L. S. di Troppi \& B. Pawlick-Skowronska (Eds.), Abiotic Stresses in Plants (pp. 23-52). Klumer Academic Publischers Box 17, 3300 AA Dordrecht. The Netherlands.

Carlberg, I., \& Mannervik, B. (1985). Glutathione-reductase. Methods Enzymol, 113, 484-490.

Chaves, M. M., Flexas, J., \& Pinheiro, C. (2009). Photosynthesis under drought and salt stress: regulation mechanisms from whole plant to cell. Annals of Botany, 103, 551-560. http://dx.doi.org/10.1093/aob/mcn125

Chen, X., Song, F., Liu, F., Tian, C., Liu, S., Xu, H., \& Zhu, X. (2014). Effect of different arbuscular mycorrhizal fungi on growth and physiology of maize at ambient and low temperature regimes. The Scientific World Journal, Article ID 956141. http://dx.doi.org/10.1155/2014/956141

Equiza, M. A., Miravé, J. P., \& Tognietti, J. A. (2001). Morphological, anatomical and physiological responses related to differential shoot root growth inhibition at low temperature in spring and winter wheat. Annals of Botany, 87, 67-76. http://dx.doi.org/10.1006/anbo.2000.1301

Ercoli, L., Mariotti, M., Masoni, A., \& Arduini, I. (2004). Growth responses of sorghum plants to chilling temperature and duration of exposure. Europ. J. Agronomy, 21, 93-103. http://dx.doi.org/10.1016/S1161-0301(03)00093-5

Foyer, C. H., \& Noctor, G. (2011). Ascorbate and glutathione: The heart of the redox hub. Plant Physiology, 155, 2-18. http://dx.doi.org/10.1104/pp.110.167569 
Gao, J., Jiang, N., Qin, X., Zhu, X., Ai, T., Peng, T., ... Chen, F. (2013) . Physiological and metabolic responses of Jatropha to chilling stress. International Journal of Agriculture \& Biology, 15, 871-877.

Garbero, M., Andrade, A., Reinoso, H., Fernández, B., Cuesta, C., Granda, V., ... Pedranzani, H. (2012). Differential effect of short-term cold stress on growth, anatomy, and hormone levels in cold-sensitive vs. -resistant cultivars of Digitaria eriantha. Acta Physiologiae Plantarum, 34, 2079-2091. http://dx.doi.org/10.1007/s11738-012-1007-x

Garbero, M., Pedranzani, H., Zirulnik, F., Molina, A., Pérez-Chaca, M. V., Vigliocco, A., \& Abdala, G. (2011). Short-term cold stress in two cultivars of Digitaria eriantha: Effects on stress-related hormones and antioxidant defense system. Acta Physiologiae Plantarum, 33, 497-507. http://dx.doi.org/10.1007/s11738-010-0573-z

Giovannetti, M., \& Mosse, B. (1980). An evaluation of techniques for measuring vesicular-arbuscular infection in roots. New Physiologist, 84, 489-500. http://dx.doi.org/10.1111/j.1469-8137.1980.tb04556.x

Haldimann, P. (1999). How do changes in temperature during growth affect leaf pigment composition and photosynthesis in Zea mays genotypes differing in sensitivity to low temperature? Journal of Experimental Botany, 50, 543-550. http://dx.doi.org/10.1093/jexbot/50.333.543

Haldimann, P., Fracheboud, Y., \& Stamp, P. (1996). Photosynthetic performance and resistance to photoinhibition of Zea mays L. leaves grown al sub-optimal temperature. Plant, Cell and Environment, 19, 85-92. http://dx.doi.org/10.1111/j.1365-3040.1996.tb00229.x

Halliwell, B. H., \& Gutteridge, J. M. C. (2007). Free Radicals in Biology and Medicine (4th ed.). Oxford University press.

Hamilton, E. W., \& Heckathorn, S. A. (2001). Mitochondrial adaptations to $\mathrm{NaCl}$ stress: Complex I is protected by anti-oxidants and small heat shock proteins, whereas Complex II is protected by proline and betaine. Plant Physiology, 126, 1266-1274. http://dx.doi.org/10.1104/pp.126.3.1266

Heller, J. (1996). Physic nut, Jatropha curcas. Promoting the conservation and use of underutilized and neglected crops 1 (p. 66). IPGRI, Rome, Italy.

Kumar, A., Sharma S., \& Mishra, S. (2010). Influence of arbusular mycorrhizal (AM) fungi and salinity on seedling growth, solute accumulation, and mycorrhizal dependency of Jatropha curcas L. J Plant Growth Regul, 29, 297-306. http://dx.doi.org/10.1007/s00344-009-9136-1

Latef, A. A. H. A., \& Chaoxing, H. (2011). Arbuscular mycorrhizal influence on growth, photosynthetic pigments, osmotic adjustment and oxidative stress in tomato plants subjected to low temperature stress. Acta Physiologiae Plantarum, 33, 1217-1225. http://dx.doi.org/10.1007/s11738-010-0650-3

Loggini, B., Scartazza, A., Brugnoli, E., \& Navari-Izzo, F. (1999). Antioxidative defense system, pigment composition and photosynthetic efficiency in two wheat cultivars subjected to drought. Plant Physiology, 119, 1091-1099. http://dx.doi.org/10.1104/pp.119.3.1091

Menezes-Benavente, L., Teixeira, F. K., Kamei, C. L. A., \& Margis-Pinheiro, M. (2004). Salt stress induces altered expression of genes encoding antioxidant enzymes in seedlings of a Brazilian indica rice (Oryza sativa L.) Plant Sci, 166, 323-331. http://dx.doi.org/10.1016/j.plantsci.2003.10.001

Minotti, G., \& Aust, S. D. (1987). The role of iron in the initiation of lipid per oxidation. Chem. Phys. Lipids, 44, 191-208. http://dx.doi.org/10.1016/0009-3084(87)90050-8

Noctor, G., \& Foyer, C. H. (1998). Ascorbate and Glutathione: keeping active oxygen under control. Annu Rev Plant Physiol Plant Mol Biol, 49, 249-279. http://dx.doi.org/10.1146/annurev.arplant.49.1.249

Oliveira, J. G., da Costa Aguiar Alves, P. L., \& Vitória, A. P. (2009). Alterations in chlorophyll a fluorescence, pigment concentrations and lipid peroxidation to chilling temperature in coffee seedlings. Environmental and Experimental Botany, 67, 71-76. http://dx.doi.org/10.1016/j.envexpbot.2009.05.007

Oxborough, K., \& Baker, N. R. (1997). Resolving chlorophyll a fluorescence images of photosynthetic efficiency into photochemical and non-photochemical components: calculation of $q P$ and $F^{\prime} v / F^{\prime} m$ without measuring F'o. Photosynthesis Research, 54, 135-142. http://dx.doi.org/10.1023/A:1005936823310

Philips, J. M., \& Hayman, D. S. (1970). Improved procedure of clearing roots and staining parasitic and vesicular-arbuscular mycorrhizal fungi for rapid assessment of infection. Transaction of the British Mycological Society, 55, 158-160. http://dx.doi.org/10.1016/S0007-1536(70)80110-3 
Porcel, R., Aroca, R., Azcón, R., \& Ruiz-Lozano J. M. (2006). PIP aquaporin gene expression in arbuscular mycorrhizal Glycine max and Lactuca sativa plants in relation to drought stress tolerance. Plant Molecular Biology, 60, 389-404. http://dx.doi.org/10.1007/s11103-005-4210-y

Porcel, R., Barea, J. M., \& Ruiz-Lozano, J. M. (2003). Antioxidant activities in mycorrhizal soybean plants under drought stress and their possible relationship to the process of nodule senescence. New Phytologist 157: 135-143. http://dx.doi.org/10.1046/j.1469-8137.2003.00658.x

Prakash, A. R., Patolia, J. S., Chikara, J., \& Boricha, G. N. (2007). Floral biology and flowering behaviour of Jatropha curcas. Fact seminar on Jatropha curcas L.: Agronomy and Genetics. Wageningen, The Netherland, March 26-28, 2007, Fact Foundation.

Ruiz-Lozano, J. M., Porcel, R., Azcón, R., \& Aroca, R. (2012). Regulation by arbuscular mycorrhizae of the integrated physiological response to salinity in plants: new challenges in physiological and molecular studies. Journal of Experimental Botany, 63, 4033-4044. http://dx.doi.org/10.1093/jxb/ers126

Ruiz-Sánchez, M., Armada, E., Munoz, Y., García de Salamone, I., Aroca, R., Azcón, R., \& Ruiz-Lozano, J. M. (2011). Azospirillum and arbuscular mycorrhizal colonization enhanced rice growth and physiological traits under well-watered and drought conditions. Journal of Plant Physiology, 168, 1031-1037. http://dx.doi.org/10.1016/j.jplph.2010.12.019

Ruiz-Sánchez, M., Aroca, R., Yaumara, M., Polon, R., \& Ruiz Lozano, J. M. (2010). The arbuscular mycorrhizal symbiosis enhances the photosynthetic efficiency and the antioxidative response of rice plants subjected to $\begin{array}{lllll}\text { drought stress. } & \text { Journal of Plant }\end{array}$ http://dx.doi.org/10.1016/j.jplph.2010.01.018

Scheibe, R., \& Beck, E. (2011). Drought, desiccation, and oxidative stress. In U. Lüttge et al. (Eds.), Plant Desiccation Tolerance, Ecological Studies (Vol. 215, pp. 209-231). Springer-Verlag, Berlin. http://dx.doi.org/10.1007/978-3-642-19106-0_11

Smith, S. E., \& Read, D. J. (2010). Mycorrhizal Symbiosis (p. 800). Academic Press.

Tong, L., Danwei, M, Wuyuan, D., \& Fang, C. (2005). Effects of low temperature on physiological indices of Jatropha curcas. Chinese Journal of Oil Crop Sciences, 27, 50-54.

Wu, Q. S., \& Zou, Y. N. (2009). Mycorrhiza has a direct effect on reactive oxygen metabolism of drought-stressed citrus. Plant, Soil and Environment, 55, 436-442

Zheng, Y. L., Feng, Y. L., Lei, Y. B., \& Yang, C. Y. (2009). Different photosynthetic responses to night chilling among twelve populations of Jatropha curcas. Photosynthetica, 47, 559-566. http://dx.doi.org/10.1007/s11099-009-0081-9

Zhu, X., Song, F., \& Xu, H. (2010). Influence of arbuscular mycorrhiza on lipid peroxidation and antioxidant enzyme activity of maize plants under temperature stress. Mycorrhiza, 20, 325-332. http://dx.doi.org/10.1007/s00572-009-0285-7

\section{Copyrights}

Copyright for this article is retained by the author(s), with first publication rights granted to the journal.

This is an open-access article distributed under the terms and conditions of the Creative Commons Attribution license (http://creativecommons.org/licenses/by/3.0/). 